\title{
Article \\ Chemical Composition Variations of Altered and Unaffected Coals from the Huaibei Coalfield, China: Implications for Maturity
}

\author{
Songbao Feng ${ }^{1,2}$, Qiang Wei ${ }^{1,2, *}$ and Xianqing $\mathrm{Li}^{3,4, *}$ \\ 1 School of Resources and Civil Engineering, Suzhou University, Suzhou 234000, China; \\ fengsongbao123@163.com \\ 2 National Engineering Research Center of Coal Mine Water Hazard Controlling, Suzhou 234000, China \\ 3 State Key Laboratory of Coal Resources and Safe Mining, China University of Mining and \\ Technology (Beijing), Beijing 100083, China \\ 4 College of Geoscience and Surveying Engineering, China University of Mining and Technology (Beijing), \\ Beijing 100083, China \\ * Correspondence: weiq@ahszu.edu.cn (Q.W.); Lixq@cumtb.edu.cn (X.L.)
}

check for updates

Citation: Feng, S.; Wei, Q.; Li, X. Chemical Composition Variations of Altered and Unaffected Coals from the Huaibei Coalfield, China: Implications for Maturity. Energies 2021, 14, 3028. https://doi.org/10.3390/en14113028

Academic Editor: Nikolaos Koukouzas

Received: 7 April 2021

Accepted: 22 May 2021

Published: 24 May 2021

Publisher's Note: MDPI stays neutral with regard to jurisdictional claims in published maps and institutional affiliations.

Copyright: (c) 2021 by the authors. Licensee MDPI, Basel, Switzerland. This article is an open access article distributed under the terms and conditions of the Creative Commons Attribution (CC BY) license (https:// creativecommons.org/licenses/by/ $4.0 /)$.

\begin{abstract}
The composition characteristics of altered coals in the Huaibei Coalfield, China, was investigated through a comparative analysis between altered and unaffected coals from the Wolonghu, Taoyuan and Renlou coal mines. Results indicated that the altered coals in Wolonghu coal mine are mostly anthracite coals, with a maximum vitrinite reflectance of $1.6-3.9 \%$ (average of $2.9 \%$ ). Coals from Wolonghu coal mine were mainly consisted of vitrinite (66.2-97.0\%), followed by inertinite $(2.0-4.0 \%)$ and exinite $(0.4-6.9 \%)$. Differences in volatile matter content were observed between the altered coals in Wolonghu coal mine and unaffected coals from neighboring coal mines, implying that the chemical composition and maturity of coals were changed after magmatic alteration. In addition, differences in hydrogen element were noted among the coals from Wolonghu, Renlou and Taoyuan coal mines, and the phenomenon of "deficient in hydrogen element" was observed in Wolonghu coals. The aliphatic hydrocarbon structure parameters suggested that the aliphatic chain lengths of Wolonghu coals are shorter than those of coal samples from the Renlou and Taoyuan coal mines. In addition, maturity is positively correlated with hydrogen enrichment degree, but negatively related with aliphatic hydrocarbon structure. Coals from Renlou and Taoyuan coal mines showed great weight loss with various heating rates at temperatures of $0-1000{ }^{\circ} \mathrm{C}$, whereas those from Wolonghu coal mine had less weight loss.
\end{abstract}

Keywords: chemical composition; structure of organic matter; altered coal; Wolonghu coal mine; Huaibei Coalfield

\section{Highlights}

- Detailed comparative analyses of magma altered and unaffected coals were carried out.

- Hydrogen exhibits significantly difference between the magma altered and unaffected coals.

- Aromatization degree is closely related with maximum vitrinite reflectance.

- Mass fraction of coals varies greatly between $450-1000{ }^{\circ} \mathrm{C}$ with different heating rates.

\section{Introduction}

Altered coals are commonly observed in coal mines (both surface and underground) worldwide. Differences in the geological conditions (temperature, pressure and materials) of magmatic intrusion may usually cause geochemical anomalies in coals. One example is the element exchange in coal during magmatic intrusion [1-3]. This stage enriches some harmful elements [2], but the impact on rare earths is not pronounced [4,5]. Vanadium 
(V) and chromium ( $\mathrm{Cr}$ ) from magmatic hydrothermal fluids are thus enriched in coal seams [6-9]. In addition, the relative proportion of carbon (C) increases as the magma intrusion distance increases, whereas the residual elements, such as hydrogen $(\mathrm{H})$, oxygen $(\mathrm{O})$, nitrogen $(\mathrm{N})$ and sulfur $(\mathrm{S})$, showing an opposite tendency [10-14]. Secondly, magma intrusion increases the relative content of calcite [15], while the iron-magnesia intrusion raises the content of pyrite $[16,17]$. For example, the silicon-rich hydrothermal fluids substitute clay minerals, which partially increases the conversion degree of montmorillonite to illite [9]. In addition, magma intrusion affects macerals contents and can even eliminate vitrinite [9,16-19]. With regard to molecular structure, magma intrusion causes defects in the coal molecular interlayers [20,21], thus forming a large number of cleats and amplifying the permeability of coal seams [22].

The Wolonghu coal mine located in the Huaibei Coalfield, is a typically magma intrusion coal mine that has been previously reported [23-26]. Feng et al. [6] studied the elemental characteristics of coal in the Wolonghu coal mine, and proposed that the relative contents of $\mathrm{Fe}$ and $\mathrm{Ti}$ are lower than in the upper crust, and the enrichment coefficients of $\mathrm{Ni}$ and $\mathrm{Cu}$ are greater than 1 . An et al. $[4,16]$ investigated the Raman spectral characteristics of pyrite in the rock-coal alteration zone of Wolonghu coal mine. However, systematic research on the composition and pyrolitical characteristics of organic matter in the magma-altered coals of Wolonghu coal mine is lacking. Therefore, this study aims to: (1) investigate the basic features, such as coal rank, macerals and chemical components and their variations in coals collected from the Huaibei Coalfield; (2) determine elemental differences between altered and unaffected coals from the Wolonghu, Taoyuan and Renlou coal mines; and (3) examine the change in the organic matter content of altered coals by Fourier infrared spectrometry. This work scientifically investigated the basic characteristics and revealed the variations of chemical compositions of altered and unaffected coals from the Huaibei Coalfield. The result should help promote our understanding of the differences between altered and unaffected coals, and have practical importance for the exploration and development of coal resources in the Huaibei Coalfield.

\section{Geological Setting}

Located in the Southern part of North China, the Huaibei Coalfield is one of the more important coal mining areas in China, with abundant coal resources that measure $130 \mathrm{~km}$ in length in the E-W direction and $100 \mathrm{~km}$ in S-N width and covering an area of $1.3 \times 10^{4} \mathrm{~km}^{2}$ (Figure 1a). Notably, magmatic rocks are generally limited in the Huaibei Coalfield. The coal seams of each coal mine in the Suxian Mining Area are less affected, followed by the Linhuan Mining Area. The Wolonghu coal mine is located in the south part of the Suixiao Mining Area, which is more seriously affected by magma intrusion, while the neighboring Taoyuan and Renlou coal mines are not affected by magmatic activities. In addition, the total thickness of coal-bearing strata of the Taoyuan and Renlou coal mines is approximately $1200 \mathrm{~m}$. The coal seams exhibit 10-25 layers and mainly comprise the Shanxi Formation, Lower Shihezi Formation, and Upper Shihezi Formation. In the sedimentary system of the Shanxi Formation, the dominant shallow sea and bay sedimentary environment was transformed into a delta sedimentary environment, and peat swamping occurred on the vast delta plain. Therefore, the Nos. 7, 8, and 10 coal seams with good continuity and stable thickness were formed successively.

The Wolonghu coal mine is located on the western margin of the Xusu arcuate structure and is bordered by the Fengguo fault to the west (Figure 1b). The strata, including the Carboniferous Taiyuan Formation, Permian Shanxi Formation, Lower Shihezi Formation, Upper Shihezi Formation, Shiqianfeng Formation, and Upper Neogene and Quaternary, are penetrated by boreholes in the mining area. The coal-bearing strata are Carboniferous and Permian. No minable coal seams were exploited in the former, but the latter includes the Shanxi and Upper and Lower Shihezi Formations. Magmatic rocks have generally developed in the mining area and have severely altered the Nos. 6, 7, 8, and 10 coal seams. The magma flow goes from south to north along the fault belts and coal seams. The 
plutonic rocks of the Wolonghu coal mine are the products of magmatic activity during the Yanshan orogeny of the late Cretaceous. Moreover, the Yanshanian magmatic intrusion can be divided into four stages $[6,26]$. The first stage is neutral magmatic rock, which is closely related to the E-W structure and distributed near the Subei fault. The coals from the Wolonghu coal mine were altered by magma during this period ( $>145 \mathrm{Ma}$ ) [26]. The fourth stage is basic and ultrabasic magmatic rocks, which are found near the Zhahe syncline and Sunan Syncline in the east of Huaibei Coalfield. Although located in this area, the magma has minimal influence on the coal seams of Taoyuan and Renlou coal mines. Thus, all the selected coals from Wolonghu, Taoyuan and Renlou coal mines can be compared to reveal the influence of magma intrusion on coal seams.

(a)
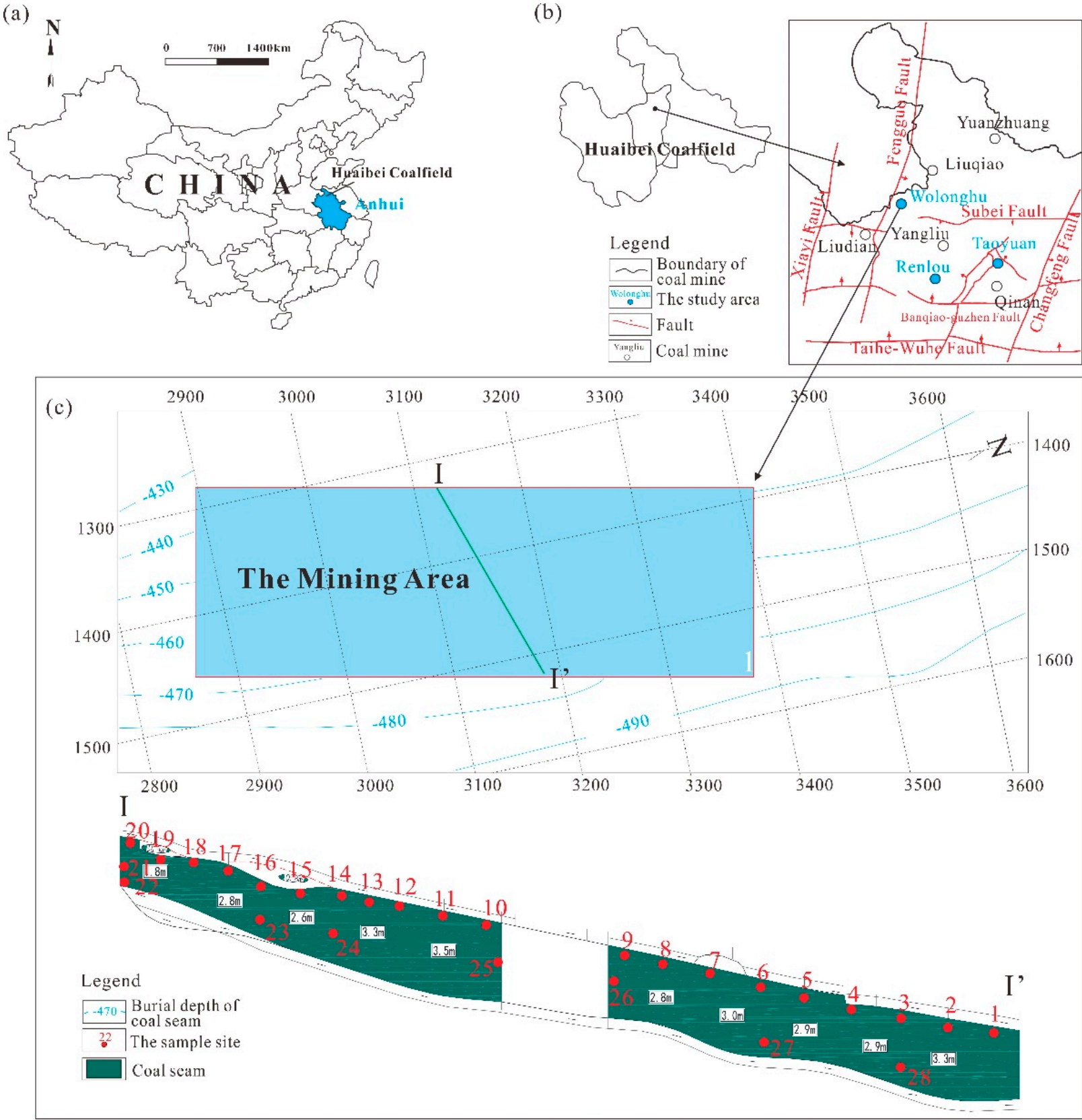

Figure 1. Location map (a) and sample collection $(\mathbf{b}, \mathbf{c})$ of coals from Wolonghu coal mine in the Huaibei Coalfield.

(b)

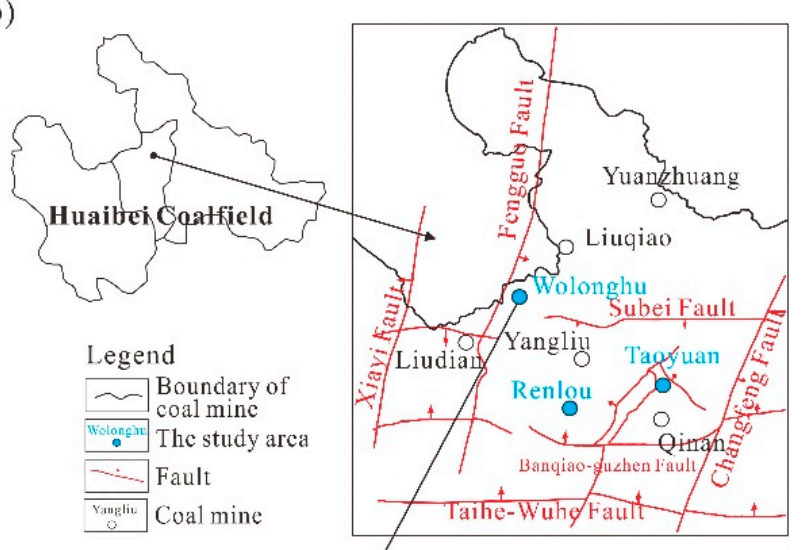

00 


\section{Samples and Methods \\ 3.1. Samples Collection}

On the basis of the distribution of magma-altered coal mines, 28 coal samples were collected from Wolonghu coal mines. The sampling sites are shown in Figure 1c. From the perspective of the mining faces, the coal samples collected from the Wolong coal mine are all altered coals. For comparison, eight and 11 unaffected coal samples were gathered from the Taoyuan and Renlou coal mines, respectively. The number of samples collected varied due to the different development conditions of the working face in each coal mine; however, this does not affect the analysis. The selected coals are dominated by bright coal, followed by semi-bright coal. The coals have developed staggered or stepped fracture and occasionally sliding surfaces. All the collected coal samples were analyzed by means of proximate, maceral analyses, and maximum vitrinite reflectance $\left(R_{\max }\right)$ test based on the China National Standard GB/T212-2008, GB/T8899-2013, and GB/T6948-1998, respectively. Prior to measurement, the polished flat surfaces of all selected coals were dried, and the desmocollinite was selected as the object. Moreover, the maceral and mineral contents were quantified by means of grid statistics after compositional characterization. All results from the above measurements are listed in Table 1.

Table 1. Results of the proximate, maceral and $R_{\max }$ analyses of the selected coals in the Huaibei Coalfield.

\begin{tabular}{|c|c|c|c|c|c|c|c|c|}
\hline \multirow{2}{*}{ Coal Mine } & \multicolumn{4}{|c|}{ Proximate Analysis (wt. \%) } & \multicolumn{3}{|c|}{ Maceral Analysis (vol. \%) } & \multirow{2}{*}{$R_{\max }(\%)$} \\
\hline & Moisture & Ash & Volatile & Fixed Carbon & Vitrinite & Inertinite & Exinite & \\
\hline \multirow{2}{*}{ Wolonghu } & $\underline{1.6-6.1}$ & $\underline{3.9-38.4}$ & $\underline{4.9-10.7}$ & $\underline{50.1-87.8}$ & $\underline{66.2-97.0}$ & $2.0-34.0$ & $\underline{0.4-6.9}$ & $\underline{1.6-3.9}$ \\
\hline & 3.0 & 16.9 & 8.3 & 71.9 & 80.6 & 16.8 & 2.54 & 2.9 \\
\hline \multirow{2}{*}{ Renlou } & $\underline{0.7-2.8}$ & $\underline{6.3-56.2}$ & $\underline{17.3-39.8}$ & $\underline{23.8-61.0}$ & $\underline{64.9-85.7}$ & $\underline{4.2-31.4}$ & 3.7-15.9 & $\underline{0.5-1.0}$ \\
\hline & $\overline{2.1}$ & $\overline{19.0}$ & 29.2 & 49.7 & 79.8 & $\overline{13.8}$ & 7.1 & $\overline{0.8}$ \\
\hline \multirow{2}{*}{ Taoyuan } & $2.2-2.9$ & $\underline{5.5-23.6}$ & $14.7-37.1$ & $\underline{46.1-65.4}$ & 70.1-82.9 & $\underline{11.4-21.5}$ & $2.3-8.4$ & $\underline{0.5-0.9}$ \\
\hline & 2.5 & 9.8 & 31.1 & 56.6 & 75.8 & 16.9 & 5.3 & 0.7 \\
\hline
\end{tabular}

\subsection{Ultimate Analysis}

Element content was measured using an elemental analyzer (MACRO Cube, Vario, Frankfurt, Germany) equipped with an infrared detector following the China National Standard GB/T 476-91. Prior to measurement, all the coals were dried and smashed to a diameter of 200 mesh, and each coal sample weighed approximately $1 \mathrm{~g}$. The samples were tested while the instrument increased the set temperature over a short time of $<45 \mathrm{~min}$. The measured values were calculated according to the above standard operation guide, and the detection range for the elements was $>100 \mathrm{ppm}$.

\subsection{Fourier-Transform Infrared Spectroscopy (FTIR) Analysis}

The organic matter structure of the coals was studied through Fourier infrared spectrometry using American Society of Testing Materials Standard ASTM C1441-2013. Prior to measurement, all the coals were powered to a diameter of approximately 200 mesh and coal sample of 1-2 g weight each were prepared. The coals and the dried potassium bromide were placed in an agate mortar at a volume ratio of 1:180, and then ground and scanned under the Fourier infrared spectrometer lamp with a spectral range of $400-4000 \mathrm{~cm}^{-1}$ and a resolution of $2 \mathrm{~cm}^{-1}$. During measurements, each coal sample was scanned 32 times. After scanning, the baseline of the Fourier infrared spectrum was processed, and peaks were fitted using the Origin 9.0 software (OriginLab, Northampton, MA, USA). The area ratios of several special peaks in the infrared spectrum can reflect the differences of each sample. On the basis of the hydrocarbon generation and evolution of functional groups, the parameters of fat structure and hydrogen enrichment degree were computed as follows:

$$
K_{a l}=A\left(2920 \mathrm{~cm}^{-1}\right) / A\left(2850 \mathrm{~cm}^{-1}\right)
$$


where $K_{a l}$ is the aliphatic hydrocarbon structure parameter, $A\left(2920 \mathrm{~cm}^{-1}\right)$ is the area of the $\mathrm{CH}$ stretching vibration peak in the aliphatic chain or alicyclic ring, $A\left(2850 \mathrm{~cm}^{-1}\right)$ is the area of the $\mathrm{CH}_{2}$ stretching vibration peak. It is worth noting that a high $K_{a l}$ value implies a long fat chain.

$$
I_{H O}=\left(\mathrm{A}\left(\mathrm{CH}_{2}\right)+\mathrm{A}\left(\mathrm{CH}_{3}\right)\right) / \mathrm{A}(\mathrm{C}=\mathrm{C})
$$

where $I_{H O}$ is the hydrogen enrichment degree parameter that represents the hydrocarbon generation capacity and aliphatic hydrocarbon content; and $\mathrm{A}\left(\mathrm{CH}_{2}\right), \mathrm{A}\left(\mathrm{CH}_{3}\right)$, and $\mathrm{A}(\mathrm{C}=\mathrm{C})$ are the area of stretching vibration absorption peaks of $\mathrm{CH}_{3}$ and $\mathrm{CH}_{2}$ and corresponding to the wavenumbers of 2950,2920 , and $2850 \mathrm{~cm}^{-1}$, respectively.

\subsection{Thermogravimetric Analysis}

Thermogravimetric experiment was conducted by TG-DSC (Labsys Evo, Lyon, France) following the China National Standard GB/T 27761-2011. This instrument was equipped with a temperature sensor, and the resolution is $\pm 0.1^{\circ} \mathrm{C}$. Its temperature measurement range was 0 to $1200{ }^{\circ} \mathrm{C}$, and the carrier gas was nitrogen with purity of $>99.9 \%$. Prior to measurement, a $10 \pm 0.1 \mathrm{mg}$ sample of dried coal with a diameter of approximately 200 mesh was prepared. The temperature of each coal sample was increased from room temperature to $<1200{ }^{\circ} \mathrm{C}$ at heating rates of $2{ }^{\circ} \mathrm{C} / \mathrm{min}, 5^{\circ} \mathrm{C} / \mathrm{min}$ and $10^{\circ} \mathrm{C} / \mathrm{min}$.

\section{Results}

\subsection{Coal Rank and Basic Characteristics of Coals}

The coal rank and basic features of coals in the Wolonghu coal mine are listed in Table 1. The $R_{\max }$ is in the range of $1.6 \%$ to $3.9 \%$ with an average value of $2.9 \%$. The selected coal samples with $R_{\max }$ values of $<2.5 \%$ accounted for $21.4 \%$ (Figure 2); of which $R_{\max }$ values of $>2.5 \%$ yield values of $78.6 \%$ predominated in the Wolonghu coal mine. By contrast, the $R_{\max }$ values of coals from the Renlou and Taoyuan coal mines are $0.5-1.0 \%$ (average of $0.8 \%$ ) and $0.5-0.9 \%$ (average of $0.7 \%$ ), respectively (Table 1 ). This finding suggests that almost of all the magma-altered coals in the Wolonghu coal mine are anthracite coals, whereas the unaffected coals of the latter two coal mines are low-rank bituminous coals.

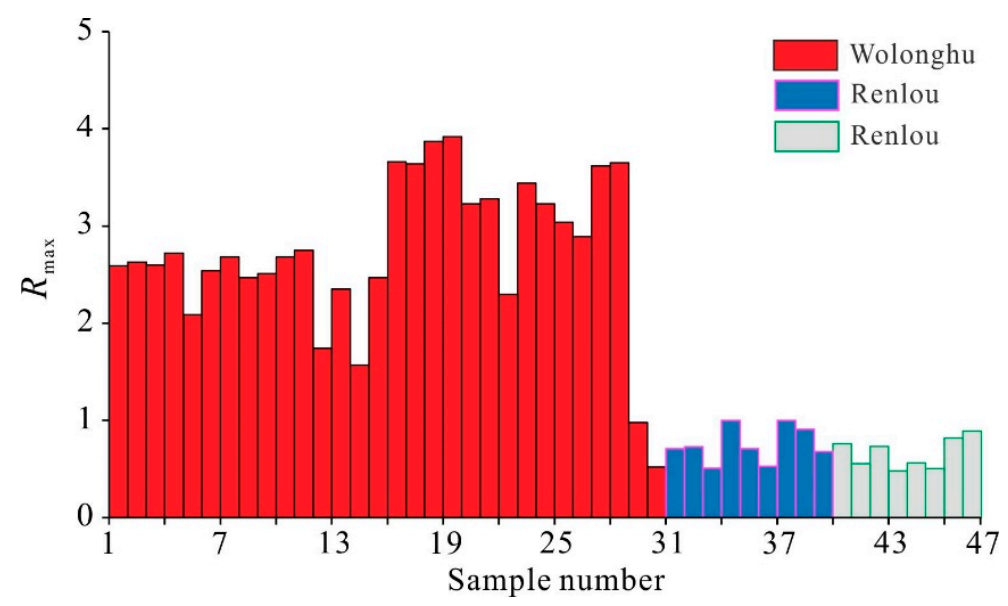

Figure 2. Distributions of maximum vitrinite reflectance of coals from the Huaibei Coalfield.

Additional information can be obtained from the maceral components and chemical composition data. The maceral components of coals from the Wolonghu coal mine consisted of vitrinite (66.2-97.0\%; average of $80.6 \%$ ), while the inertinite and exinite contents are $2-33.96 \%$ (average of $16.8 \%$ ) and $0.4-6.9 \%$ (average of $2.5 \%$ ), respectively (Figure 3a). Moreover, the percentages of vitrinite matters in coals from the Renlou and Taoyuan coal mines are $64.9-85.7 \%$ (average of $79.8 \%$ ) and $70.1-82.9 \%$ (average of $75.8 \%$ ), respectively. These results show that the coals in the Wolonghu coal mine are predominantly composed of fixed carbon (50.1-87.8\%; average of $72.0 \%$ ), followed by ash (3.9-38.4\%; average of 
$16.9 \%)$, volatile matter (4.9-10.7\%; average of $8.3 \%$ ) and moisture (1.6-6.1\%; average of $3.0 \%$ ). The magma-altered coals from the Wolonghu coal mine have lower volatile matter content than the unaffected coals from the Renlou (17.3-39.8\%; average of 29.2\%) and Taoyuan (14.7-37.1\%; average of 31.1\%) coal mines, but have higher fixed carbon than the latter two coal mines, with values of $50.1-87.8 \%$ and a mean value of $71.9 \%$ (Figure 3b). Notably, the volatile matter content in most coals from the Wolonghu coal mine is lower than $10 \%$ with several exceptions (Table 1), and these coals are characterized by relatively low ash and fixed carbon contents. The moisture contents of unaffected coals from the Renlou and Taoyuan coal mines are lower than those of almost all coals from the Wolonghu coal mine with values of $0.7-2.8 \%$ (average, 2.1\%) and 2.2-2.9\% (average of $2.5 \%$ ), respectively.

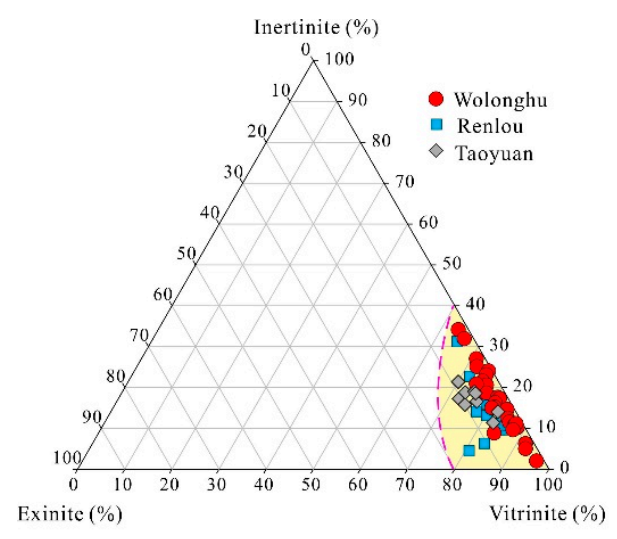

(a)

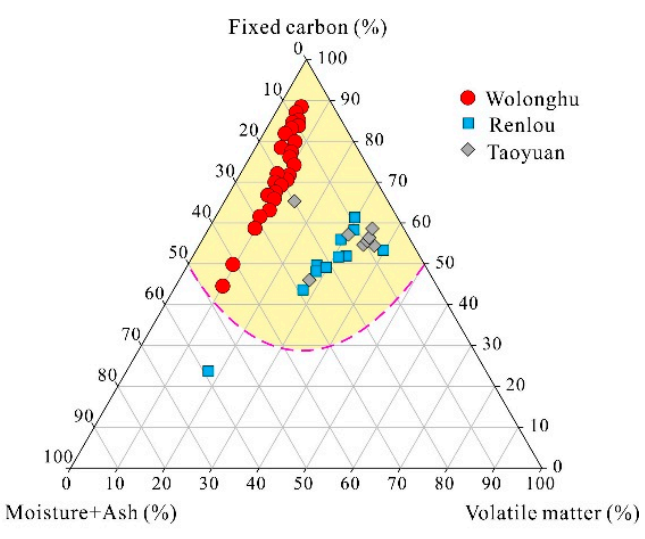

(b)

Figure 3. Maceral components (a) and chemical compositions (b) of the selected coal samples in the Huaibei Coalfield.

\subsection{Element Contents of Coals}

The elemental contents of the selected coal samples are listed in Table 2. The Wolonghu coals predominately consisted of $C$, ranging from $53.3 \%$ to $86.1 \%$ with a mean value of $72.5 \%$. Its $\mathrm{N}, \mathrm{O}$ and $\mathrm{S}$ element contents are $1.1-2.4 \%$ (average of $1.8 \%$ ), $0.2-7.6 \%$ (average of $5.1 \%$ ) and $0.3-0.8 \%$ (average of $0.4 \%$ ), respectively. Notably, the distributions of the aforementioned elements in Wolonghu coals are similar to those in the coals from the Renlou and Taoyuan coal mines (Figure 4). However, the $\mathrm{H}$ element exhibits different intervals for the above three coal mines, that is, coals from Wolonghu, Renlou and Taoyuan coal mines are $1.9-3.5 \%$ (average of $2.8 \%$ ), $4.2-4.8 \%$ (average of $5.1 \%$ ) and $4.8-6.0 \%$ (average of $5.5 \%$ ), respectively (Figure $4 \mathrm{c}$ ).

Table 2. Element contents of the selected coal samples from the Huaibei Coalfield.

\begin{tabular}{cccccc}
\hline \multirow{2}{*}{ Coal Mine } & \multicolumn{5}{c}{ Conventional Element Content $(\%$, daf) } \\
\cline { 2 - 6 } & $\mathbf{C}$ & $\mathbf{H}$ & $\mathbf{O}$ & $\mathbf{N}$ & $\mathbf{S}$ \\
\hline \multirow{2}{*}{ Wolonghu } & $\frac{53.3-86.1}{72.5}$ & $\frac{1.9-3.5}{2.8}$ & $\frac{0.2-7.6}{5.1}$ & $\frac{1.1-2.4}{1.8}$ & $\frac{0.3-0.8}{0.4}$ \\
\hline \multirow{2}{*}{ Renlou } & $\frac{61.6-81.3}{72.3}$ & $\frac{4.2-5.7}{4.8}$ & $\frac{2.0-7.8}{3.7}$ & $\frac{1.4-2.4}{2.0}$ & $\underline{0.1-0.9}$ \\
\hline \multirow{2}{*}{ Taoyuan } & $\frac{73.2-82.4}{73.4}$ & $\frac{4.8-6.0}{5.5}$ & $\frac{2.9-5.7}{4.2}$ & $\frac{1.9-2.3}{2.1}$ & $\frac{0.4-1.1}{0.5}$ \\
\hline
\end{tabular}

Note: $\frac{53.3-86.1}{72.5}=\frac{\text { Minimum-Maximum }}{\text { Average }}$. 

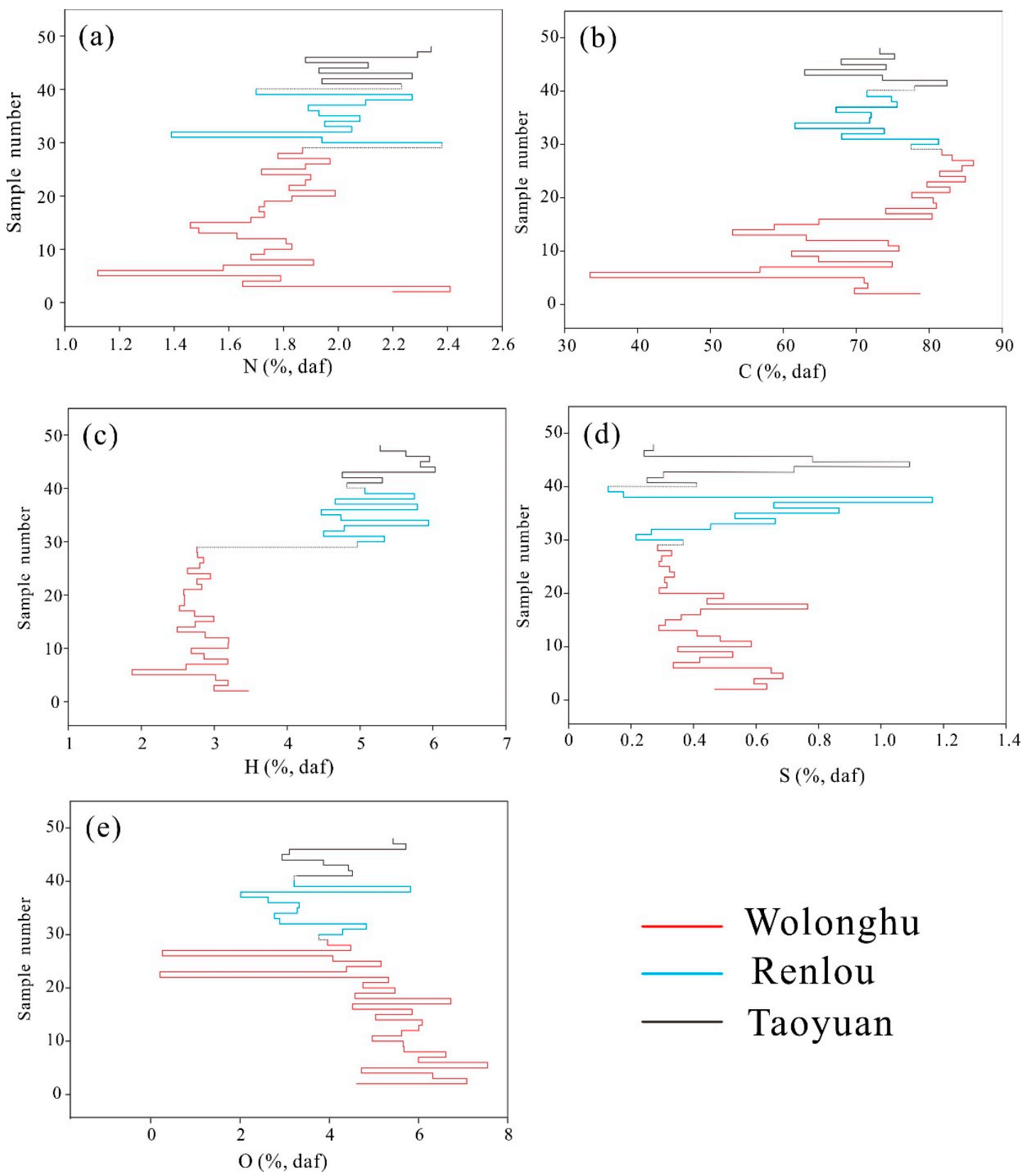

Figure 4. Element distributions of $\mathrm{N}(\mathbf{a}), \mathrm{C}(\mathbf{b}), \mathrm{H}(\mathbf{c}), \mathrm{S}(\mathbf{d})$, and $\mathrm{O}(\mathbf{e})$ in the selected coals from the Huaibei Coalfield.

\subsection{FTIR Characterisitics of Coals}

The 47 Fourier infrared spectrograms for the studied coal samples were normalized, baseline-corrected, and smoothed. Typical coal samples from the Wolonghu, Renlou and Taoyuan coal mines are listed and shown in Figure 5. The absorption peaks and trends of coals exhibit substantial differences among the aforementioned coal mines. For alkyl groups, double peaks were observed in the alkyl (C-H) region of the high-wavenumber section of coals from the Wolonghu coal mine and have developed with small absorption intensities in the measured wavenumber interval. However, the absorption intensity at relatively high wavenumber peak $\left(2920 \mathrm{~cm}^{-1}\right)$ is greater than that at lower wavenumber peak $\left(2850 \mathrm{~cm}^{-1}\right)$. The alkyl bands in the low-wavenumber section have bimodal characteristics and yield higher peak values than those in the high-wavenumber section. In addition, the absorption intensity at $1460 \mathrm{~cm}^{-1}$ (asymmetric bending vibration of $\mathrm{CH}_{2}$ and $\mathrm{CH}_{3}$ bases) is greater than that at $1380 \mathrm{~cm}^{-1}$ (symmetrical bending vibration of $\mathrm{CH}_{3}$ 
base). The alkyl groups of Wolonghu coals have similar characteristics to those from the Renlou and Taoyuan coal mines. In the high-wavenumber section, bimodal patterns and small absorption intensity can be observed. In the low-wavenumber section, the absorption intensity is higher than that in the high-wavenumber section.
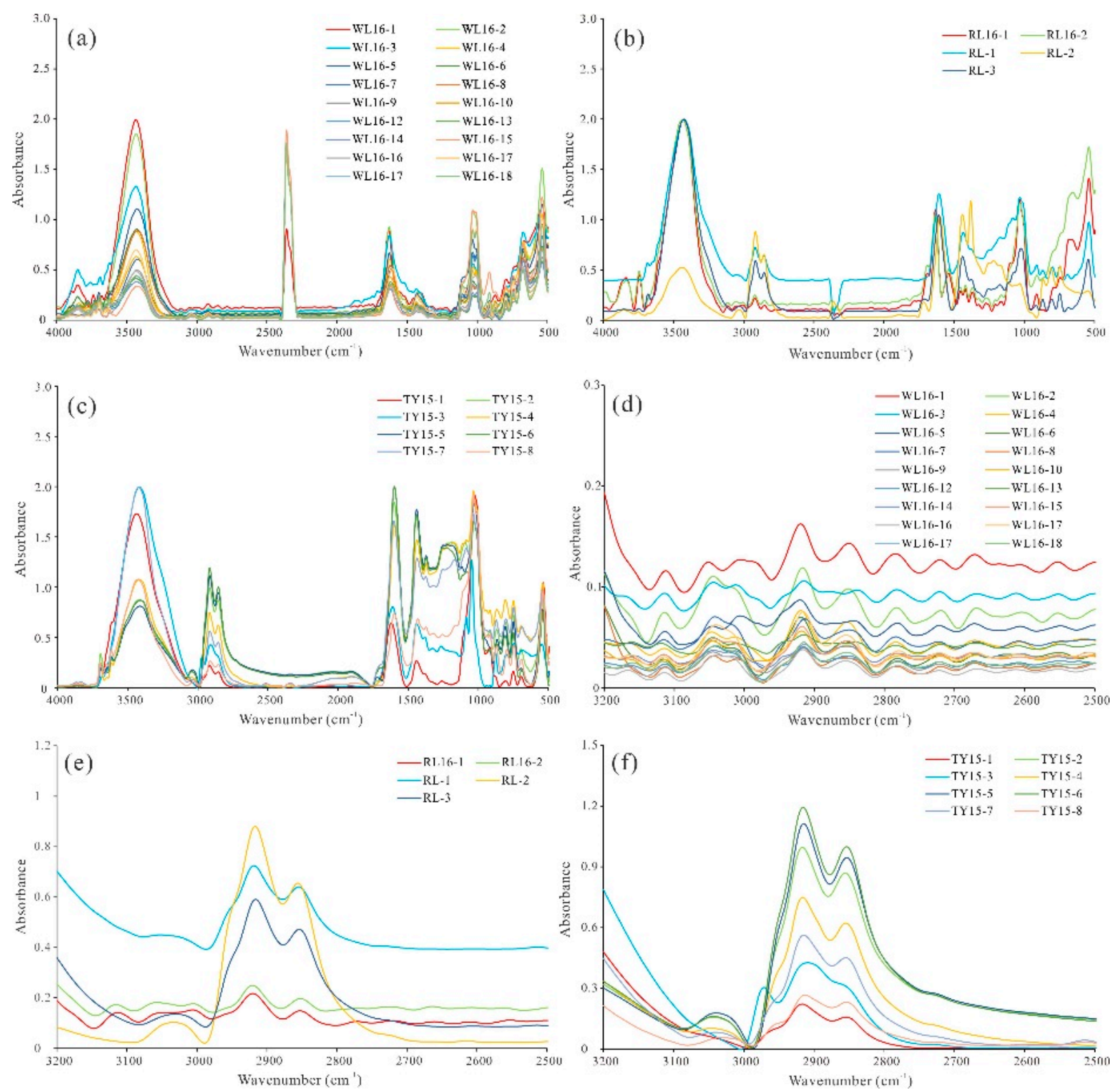

Figure 5. Infrared spectrum curves at wavenumbers of 500-4000 $\mathrm{cm}^{-1}(\mathbf{a}-\mathbf{c})$ and $2500-3200 \mathrm{~cm}^{-1}(\mathbf{d}-\mathbf{f})$ of all the selected coal samples from the Wolonghu, Taoyuan and Renlou coal mines in the Huaibei Coalfield.

Aromatic hydrocarbons (CH-based stretching vibration) in the high-wavenumber section of Wolonghu coal samples show a unimodal distribution, and the absorption peak is relatively weak. By contrast, the aromatic hydrocarbons $(\mathrm{C}=\mathrm{C})$ in the mid-wavenumber section exhibit deformations and vibrations and are characterized by a bimodal pattern with great absorption intensity. This absorption intensity is larger in a higher wavenumber $\left(1600 \mathrm{~cm}^{-1}\right)$ than in a low wavenumber $\left(1550 \mathrm{~cm}^{-1}\right)$ region. In addition, the absorption intensity of the low-wavenumber section is greater than that of the high-wavenumber region. Coal samples from the Renlou and Taoyuan coal mines show single peaks in the high-wavenumber section, but with relatively weak developed absorption intensity. Aromatic hydrocarbons show double peaks in the middle-wavenumber section, and their 
absorption intensities reach a medium degree. Moreover, the absorption intensity of aromatic hydrocarbon base in the low-wavenumber section is greater than that in the high-wavenumber section.

$K_{a l}$ and $I_{H O}$ were calculated using Equations (1) and (2), and the results are listed in Table 3. The $I_{H O}$ of coal samples in Wolonghu coal mine ranges from 0.0 to 0.8 (average of 0.1 ), that in Renlou coal mine ranges from 0.3 to 0.9 (average of 0.5 ), and that in Taoyuan coal mine it ranges from $0.3-0.6$ (average of 0.5) (Figure 6a). These findings show that the aliphatic hydrocarbon content of coal samples from the Wolonghu coal mine is smaller than those of the Renlou and Taoyuan coal mines. The $K_{a l}$ of coals from the Wolonghu coal mine is $0.8-3.1$ with an average value of 1.9, and those of coals in Renlou and Taoyuan coal mines is 1.0-2.4 (average of 1.6) and 1.1-2.1 (average of 1.1), respectively (Figure 6b). These results show that the aliphatic chains of coals from Wolonghu coal mine are longer than those of samples from the Renlou and Taoyuan coal mines. On the basis of the relatively low proportion of $\mathrm{H}$ element and the length of the aliphatic chain of coals in the Wolonghu coal mine, the result indicates that the number of aliphatic chain in Wolonghu coal mine is smaller than in the Renlou and Taoyuan coal mines.

Table 3. Infrared spectrum parameters of selected coal samples in Huaibei Coalfield.

\begin{tabular}{|c|c|c|}
\hline Coal Mine & $I_{H O}$ & $K_{a l}$ \\
\hline Wolonghu & $\frac{0.0-0.8}{\underline{0.1}}$ & $\frac{0.8-3.1}{\underline{1.9}}$ \\
\hline Renlou & $\frac{0.3-0.9}{\underline{0.5}}$ & $\frac{1.0-2.4}{1.6}$ \\
\hline Taoyuan & $\frac{0.3-0.6}{\underline{0.5}}$ & $\frac{1.1-2.1}{1.14}$ \\
\hline
\end{tabular}

Note: $I_{H O}=$ the parameter of hydrogen enrichment degree; $K_{a l}=$ the parameter of aliphatic hydrocarbon structure; $\frac{0.3-0.9}{0.5}=\frac{\text { Minimum-Maximum }}{\text { Average }}$.
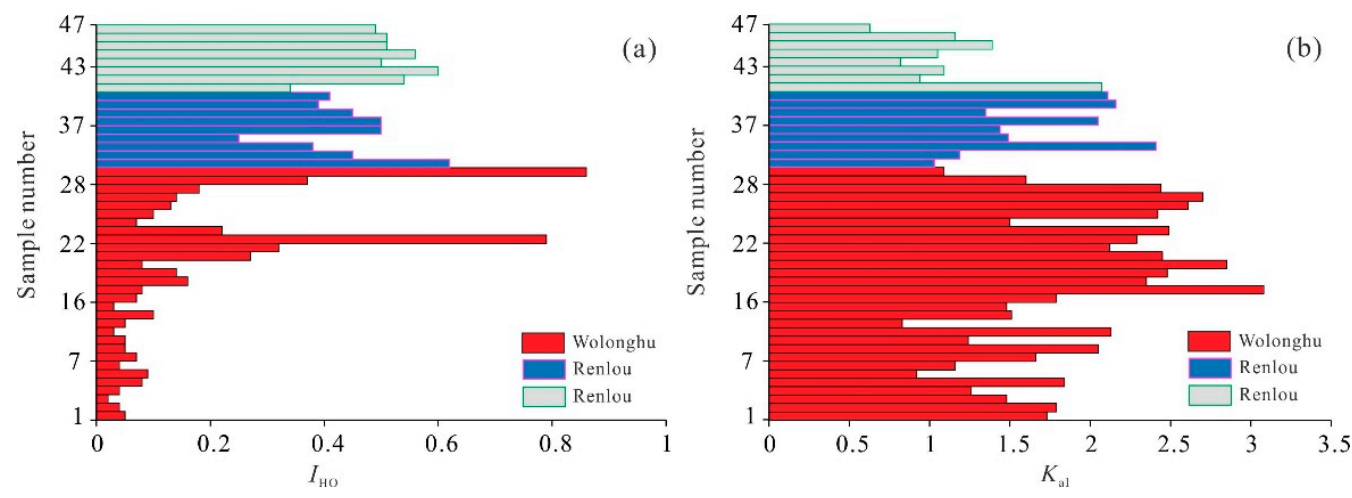

Figure 6. $I_{H O}(\mathbf{a})$ and $K_{a l}(\mathbf{b})$ distributions of the selected coal samples from the Huaibei Coalfield.

\subsection{Pyrolysis Characteristics of Coals}

Figure 7a-c show the pyrolysis behavior of coals from the Wolonghu, Renlou and Taoyuan coal mines at a heating rate of $10^{\circ} \mathrm{C} / \mathrm{min}$. The temperatures corresponding to the pyrolysis rate values of coal samples from the above three coal mines are $650^{\circ} \mathrm{C}, 450{ }^{\circ} \mathrm{C}$ and $420^{\circ} \mathrm{C}$, respectively. This finding indicates that the coal samples of the latter two coal mines require higher temperature to reach the maximum pyrolysis rate compared with the magmaaltered coals from the Wolonghu coalmine. Figure $7 \mathrm{~d}-\mathrm{f}$ reveal substantial differences in the pyrolysis rates of the coals at various heating rates. These plots indicate that the pyrolysis rate of sample WL16-17 is lower than that of samples from the Renlou and Taoyuan coal mines in the pyrolysis temperature range of $450-800{ }^{\circ} \mathrm{C}$. The pyrolysis rate decreases and then increases gradually after reaching its maximum value. The pyrolysis rates of these three samples are relatively stable and display similar change tendencies from 0 to $450{ }^{\circ} \mathrm{C}$. 
In general, a high heating rate leads to a high pyrolysis rate. For instance, the maximum pyrolysis rate is $-0.0043 \mathrm{mg} / \mathrm{min}$ at heating rate of $2{ }^{\circ} \mathrm{C} / \mathrm{min}$, which corresponds to the temperature of $640{ }^{\circ} \mathrm{C}$. The maximum pyrolysis rate is $-0.0095 \mathrm{mg} / \mathrm{min}$ at $5{ }^{\circ} \mathrm{C} / \mathrm{min}$, and the temperature is $514{ }^{\circ} \mathrm{C}$. When the heating rate is $10 \mathrm{k} / \mathrm{min}$, the maximum pyrolysis rate is $-0.0187 \mathrm{mg} / \mathrm{min}$ and the temperature is $557{ }^{\circ} \mathrm{C}$. The pyrolysis rate of sample RL16-2 has similar variation tendency with WL16-17, but the maximum pyrolysis rates are $-0.0347 \mathrm{mg} / \mathrm{min}\left(429^{\circ} \mathrm{C}\right),-0.09388 \mathrm{mg} / \mathrm{min}\left(447^{\circ} \mathrm{C}\right),-0.168546 \mathrm{mg} / \mathrm{min}\left(461{ }^{\circ} \mathrm{C}\right)$, $-0.326496 \mathrm{mg} / \mathrm{min}\left(476^{\circ} \mathrm{C}\right)$.
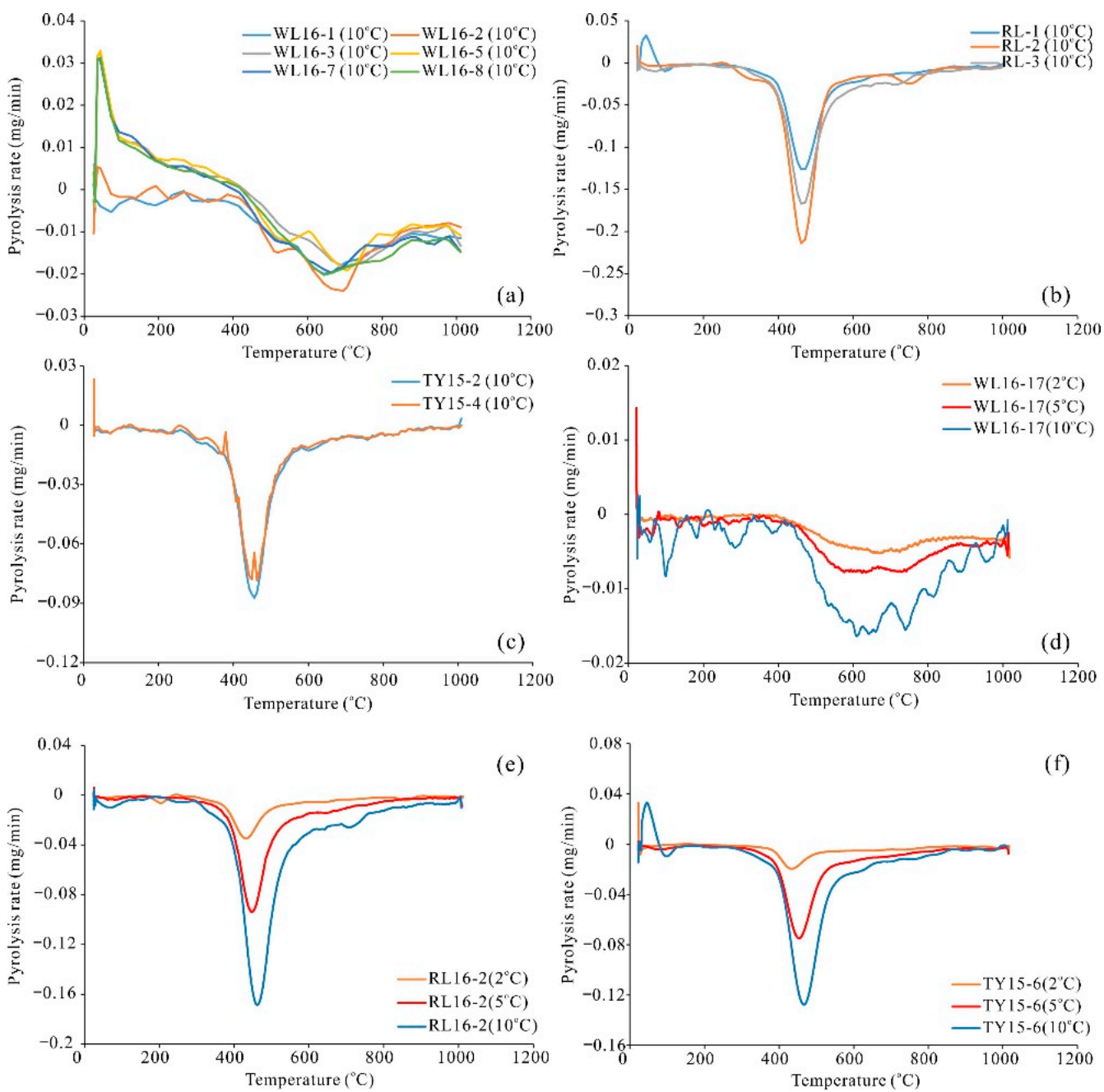

Figure 7. The pyrolysis rates at $10{ }^{\circ} \mathrm{C} / \mathrm{min}(\mathbf{a}-\mathbf{c})$ and various heating rates $(\mathbf{d}-\mathbf{f})$ of the selected coal samples from the Wolonghu, Taoyuan and Renlou coal mines in the Huaibei Coalfield.

Figure 8 shows the plots of the relationship between weight loss and temperature in coal samples from the above three coal mines. Figure $8 \mathrm{a}-\mathrm{c}$ suggest that the selected coals show varying characteristics at a heating rate of $10^{\circ} \mathrm{C} / \mathrm{min}$. Compared with the Wolonghu coals, the mass fraction of the Renlou and Taoyuan coals changed greatly and exhibited a remarkable mass loss. Figure $8 \mathrm{~d}$ shows that in the pyrolysis temperature interval of 0 to $450{ }^{\circ} \mathrm{C}$, the mass fraction of sample WL16-17 is relatively stable at various heating rates and is within the range of $-0.02-0 \%$. At 450 to $1000{ }^{\circ} \mathrm{C}$, the mass fraction changes greatly with different heating rates that follow the order: $2{ }^{\circ} \mathrm{C} / \mathrm{min}>5{ }^{\circ} \mathrm{C} / \mathrm{min}>10^{\circ} \mathrm{C} / \mathrm{min}$. The mass fraction changed from 0.99 to 0.83 at the heating rate of $2{ }^{\circ} \mathrm{C} / \mathrm{min}$ and changed from 1.00 to 0.94 at $10{ }^{\circ} \mathrm{C} / \mathrm{min}$. At the end of pyrolysis, the weight loss ratios of different heating rates are $16.6 \%, 13.2 \%$, and $10.5 \%$. For sample RL16-2 from the Renlou coal mine (Figure 8e), the initial pyrolysis temperature is approximately $300{ }^{\circ} \mathrm{C}$ and the weight-loss ratios at different 
heating rates are $27.8 \%, 27.0 \%$ and $27.1 \%$, respectively. Similarly, the weight loss ratios of sample TY15-6 from the Taoyuan coal mine are $26.5 \%, 38.4 \%$ and $32.9 \%$, respectively (Figure 8f).
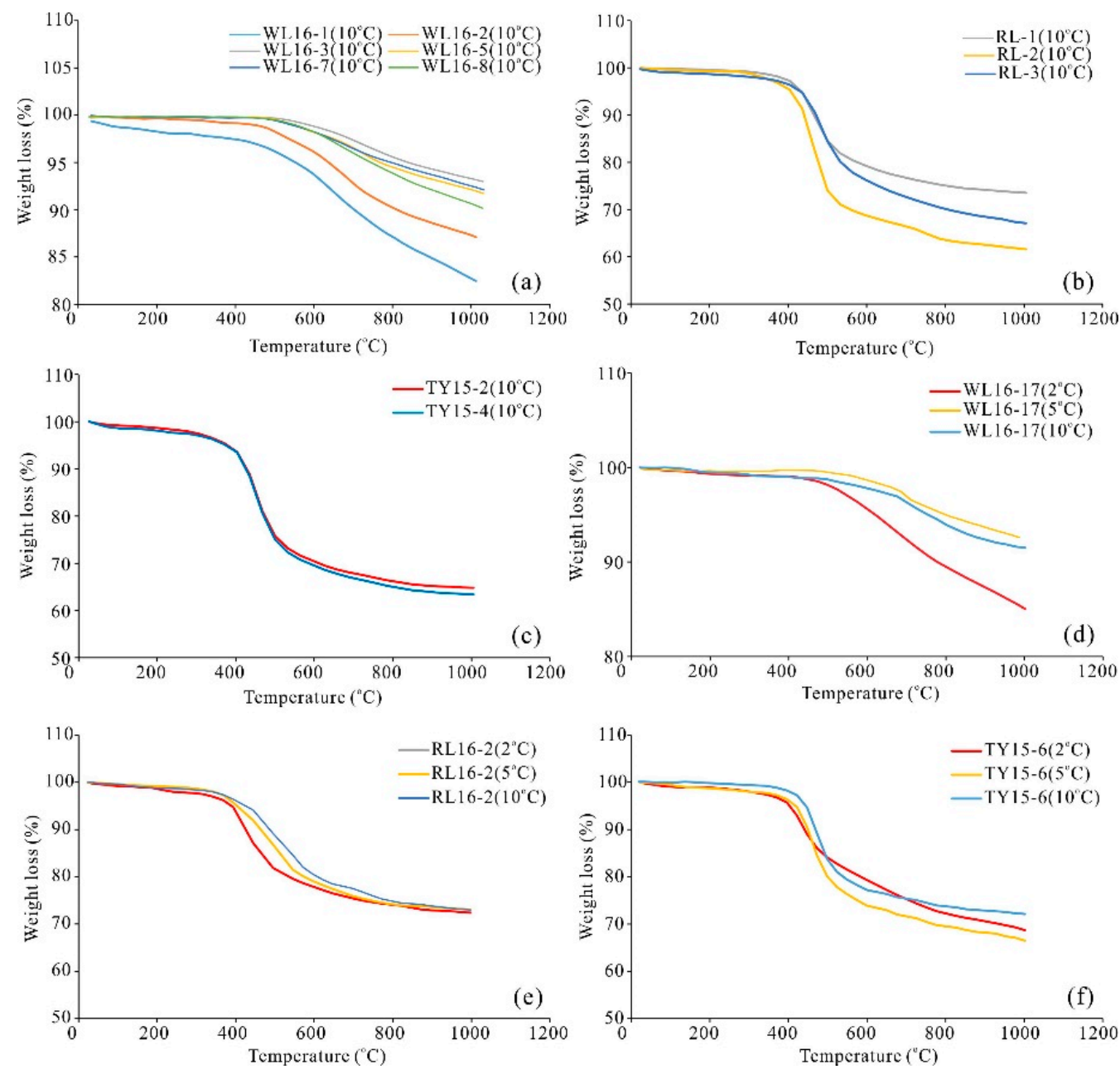

Figure 8. Weight loss at $10{ }^{\circ} \mathrm{C} / \mathrm{min}(\mathbf{a}-\mathbf{c})$ and various heating rates $(\mathbf{d}-\mathbf{f})$ of coal samples for the Wolonghu, Taoyuan and Renlou coal mines in the Huaibei Coalfield.

\section{Discussion}

\subsection{Influence of Maturity on the Basic Characteristics and Hydrogen Element Content of Coals}

Volatile matter and hydrogen contents constitute a large proportion in exinite $[2,27,28]$, and the thermal weight-loss ratio is the largest among the aforementioned macerals $[29,30]$. These phenomena explain the low exinite content in altered coals.

By examining coals with different maturities from different mining areas of China, $\mathrm{Li}$ et al. [31] pointed out that the average contents of vitrinite, inertinite and exinite for anthracite are $64.41 \%, 34.59 \%$ and $0 \%$, respectively. By contrast, the contents of vitrinite and exinite in coals from the Wolonghu coal mine are higher than those in the above studied areas, but that of inertinite is lower. Figure 9 shows the plots of relationships among $R_{\max }$, chemical and maceral components of all the selected coal samples from the Huaibei Coalfield. $R_{\max }$ is positively correlated with moisture content, but shows a weak and negative correlation with ash content (Figure $9 \mathrm{a}, \mathrm{b}$ ). The fixed carbon shows a weak but positive relationship with $R_{\max }$ (Figure 9c). However, the $R_{\max }$ shows no relationship with vitrinite, inertinite and exinite contents (Figure $9 d-f$ ), and the variations of maceral compositions may be correlated with depositional environments [11]. 

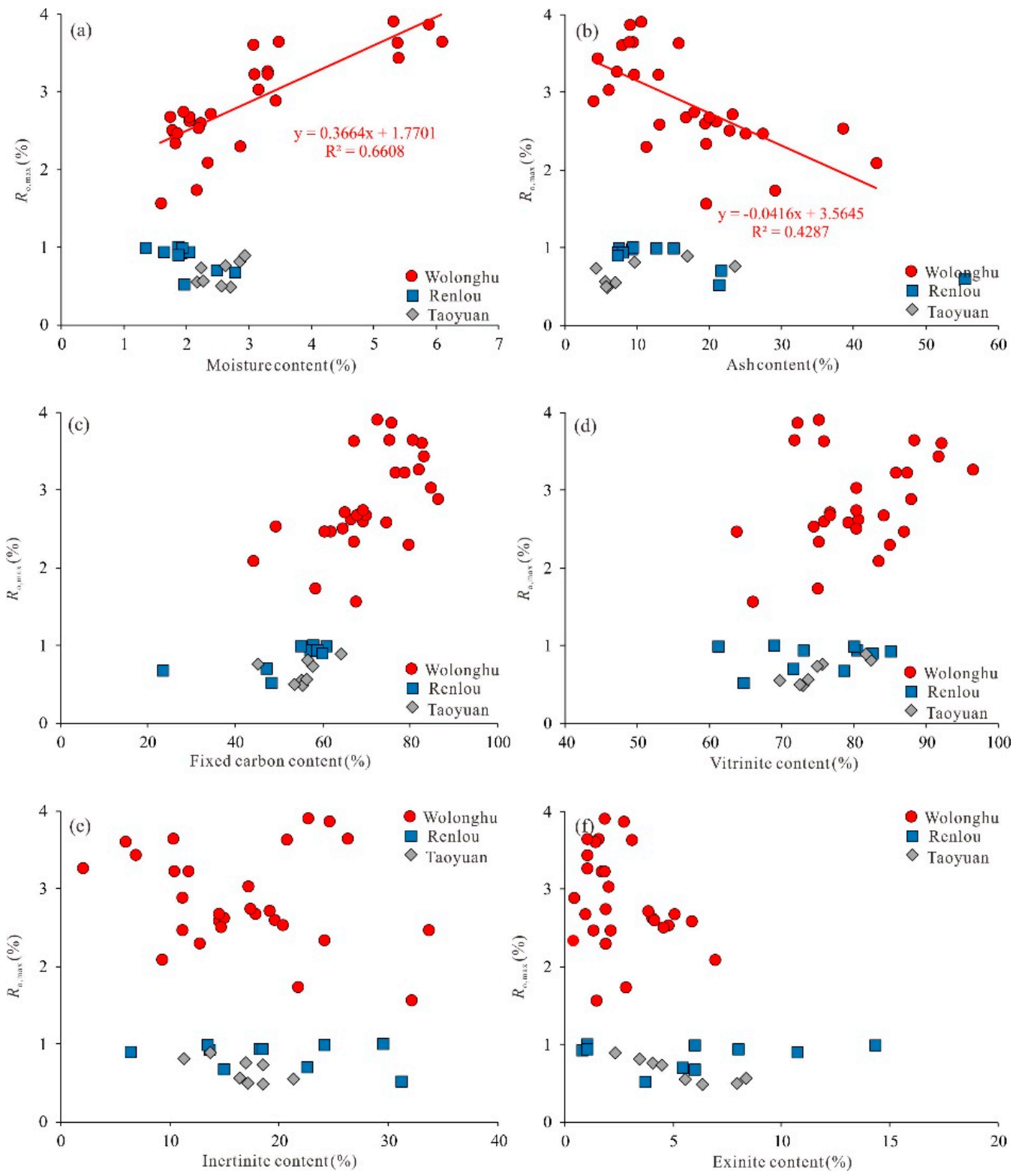

Figure 9. Correlations among chemical compositions (a-c), maceral components $(\mathbf{d}, \mathbf{e})$ and $R_{\max }(\mathbf{f})$ of the selected samples in the Huaibei Coalfield.

Figure 10 shows the negative correlation between $R_{\max }$ and volatile matter content and suggests that the volatile matter tends to decreases slowly with the increase in maturity. Remarkable variations existed in the volatile matter of coals from the aforementioned coal mines, indicating that the distribution of volatile content is indicative of maturity and magma alteration in the studied coal mines.

Persuasive evidence is shown in the plots of correlation between the conventional element contents and $R_{\max }$ of the collected coal samples. Figure 11a displays that $R_{\max }$ is positively related with $\mathrm{C}$ content but is negatively correlated with $\mathrm{H}$ element content (Figure 11b). $R_{\max }$ shows no linear relationship with $\mathrm{N}$ and $\mathrm{S}$ elements (Figure 11c,d). These findings indicate that the $\mathrm{H}$ element content decreases when $R_{\max }$ increases, that is, the $\mathrm{H}$ element in unaffected coals is higher than that in magmatically altered coal. Therefore, the phenomenon of "deficiency in $\mathrm{H}$ element" existed in the latter one. 


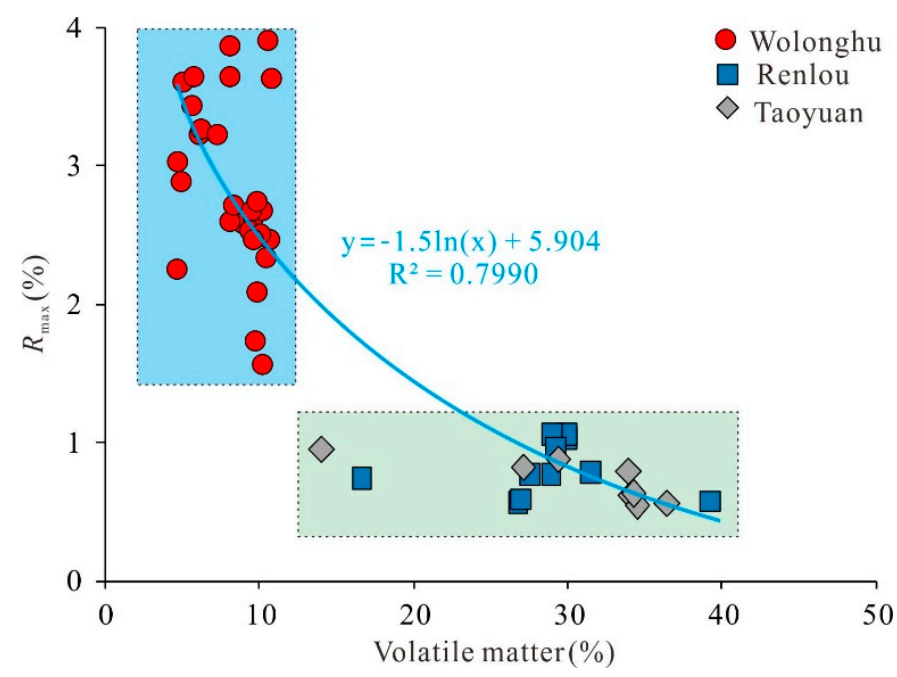

Figure 10. Correlation between volatile matter and $R_{\max }$ of the selected samples in the Huaibei Coalfield.
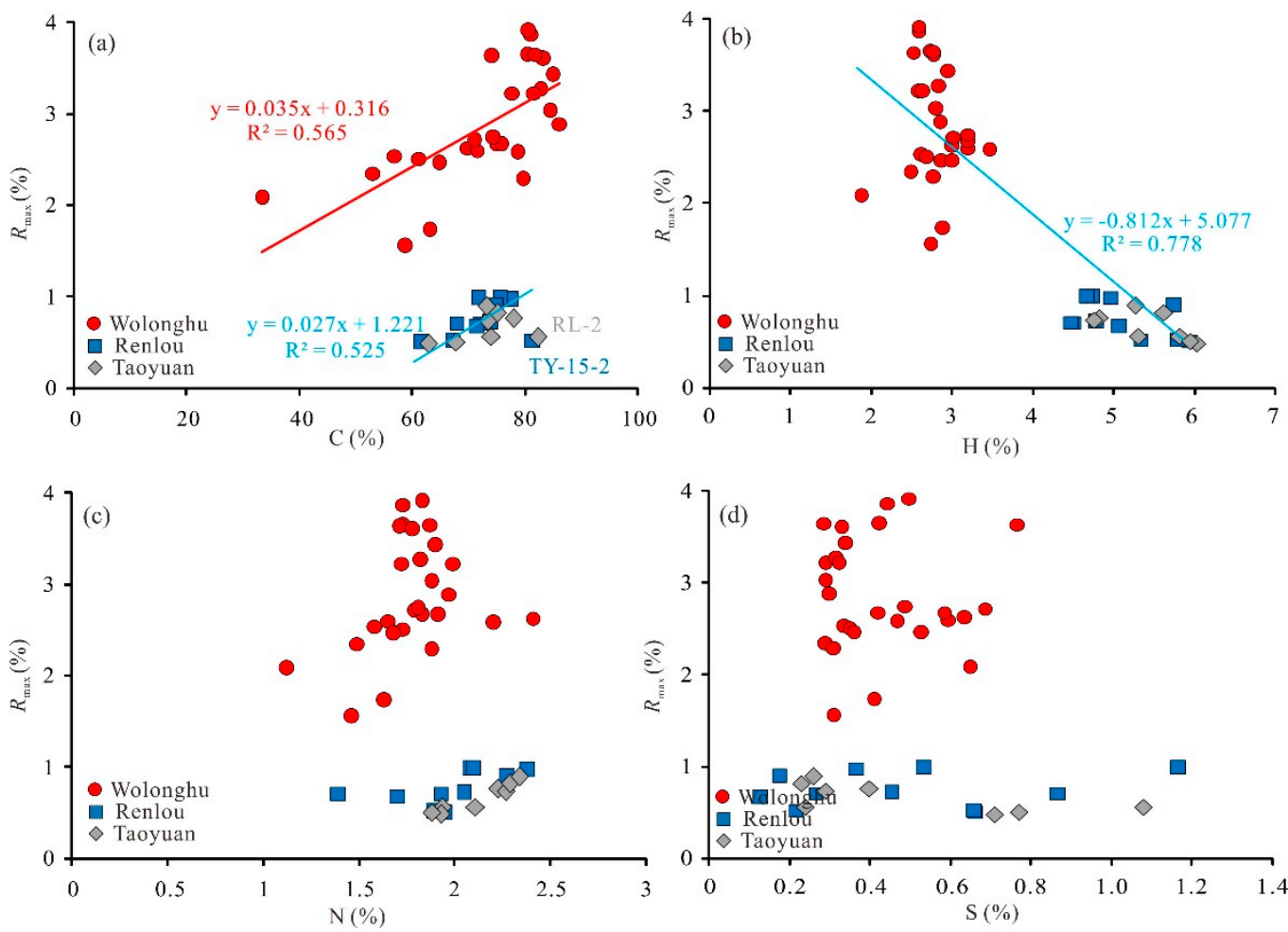

Figure 11. Correlation between conventional element contents $\mathrm{C}(\mathbf{a}), \mathrm{H}(\mathbf{b}), \mathrm{N}(\mathbf{c})$ and $\mathrm{S}(\mathbf{d})$ and $R_{\max }$ of the selected samples in the Huaibei Coalfield.

Water molecules include active molecules and inorganic ions in source rocks, which are active in the hydrocarbon generations of kerogen pyrolysis and soluble organic matter. The latter, such as $\mathrm{H}_{3} \mathrm{O}^{+}, \mathrm{H}_{5} \mathrm{O}_{2}{ }^{+}, \mathrm{H}_{7} \mathrm{O}_{3}{ }^{+}, \mathrm{H}_{9} \mathrm{O}_{4}{ }^{+}$, and $\mathrm{H}_{11} \mathrm{O}_{5}{ }^{+}$, usually do not react with stabilized organic matter, kerogen, or other parent materials through hydro-dehydration, hydro-decarboxylation and pyrolysis. With continuous burial depth that includes temperature and pressure changes, the coal is strongly squeezed, and the volume of active molecules is constantly compressed. Therefore, molecules can generate a large number of protonic acid beams $\left(\mathrm{H}^{+}\right)$.

In addition, the organic matter changes from an unstable to a stable state or polymerizes and condenses into macromolecular kerogen during diagenesis. These compounds then lose hydrogen to some extent and become partially or severely hydrogen-deficient, 
thus resulting a negatively charged organic matter. The $\mathrm{H} / \mathrm{C}$ atomic ratio of humic kerogen is generally less than 1 . The secondary kerogen after cracking is an organic molecule with a few aromatic and polycyclic arenes as the skeleton, and methyl, carboxyl, and short chain alkyl as the peripheral structure. During hydrocarbon generation, this kind of kerogen becomes strongly negatively charged, and the phenomenon of "deficiency in H element" occurs [6].

\subsection{Influence of Maturity on the Structure of Organic Matters and Pyrolysis Characteristics of Coals}

On the basis of previous studies [32-35] and the infrared spectral characteristics of coal samples from the Wolonghu, Renlou and Taoyuan coal mines, the hydrogen enrichment degree and aliphatic hydrocarbon structure parameters were chosen for the following discussions. In spectrograms, the spectral peaks are superimposed at certain positions due to the contributions of absorption bands of functional groups to the infrared spectrum; hence, the positions and boundaries of absorption peaks are difficult to determine. Hydrogen enrichment degree is indicative of aliphatic hydrocarbon and can represent the length of aliphatic chains [36]. The content of aliphatic hydrocarbons can explain the hydrocarbon generation capacity of coal [36]. In this work, the coal generation capacity of Wolonghu coal mine coal is smaller than that of the Renlou and Taoyuan coal mines, and this finding is consistent with the industrial analysis of coals (Table 2).

As shown in Figures 12 and $13, R_{\max }$ is negatively related to $I_{H O}$ in all the selected coals but is merely positively correlated with the $K_{a l}$ in the Wolonghu coals. The above analyses indicate that magma intrusion reduces the content of aliphatic hydrocarbons in coal and weakens the hydrocarbon generation capacity. However, the length of the aliphatic hydrocarbon chain is characteristically similar to that in the coal samples from the areas that have not been invaded by magma. A positive relationship between the aliphatic hydrocarbon chain length and maturity is observed for the coal samples in the intrusive zone but not for those in the non-invaded zone. In addition, the content of aliphatic hydrocarbons is related to the maturity of the collected coals in the Huaibei Coalfield.

In summary, the following hypotheses for the high initial pyrolysis temperature of coals can be put forth: (1) the inorganic components of Wolonghu coals were changed by magma. Li et al. $[31,36]$ believed that the minerals in coals inhibit the pyrolysis of various components, and the internal minerals can hinder the early ignition of two bituminous coal cokes. However, $\mathrm{Wu}$ [37] and Zhao et al. [38,39] pointed out that $\mathrm{Fe}_{2} \mathrm{O}_{3}$ and minerals have a catalytic effect on coal reactivity and $\mathrm{NH}_{3}$ release. On the basis of the aforementioned analyses and the element distributions of coals from the Huaibei Coalfield, the minerals of coals in magmatic intrusion area may hinder their pyrolysis, and the pyrolysis rate of these coals is relatively lower than that of the unaffected coals. (2) Organic components were changed during pyrolysis. The aromatic bonding increased, and the aliphatic bonds showed opposite characteristics compared with the former. The bond energy of aromatic bonds was greater than that of fatty bonds.

Three persuasive reasons for the low weight loss ratio of sample WL16-17 can be assumed. The first factor is maturity. When $R_{\max }$ is greater than 2.0 , the sample is in a high-over mature stage, indicating that the organic matter of coal has generated hydrocarbons $[2,10]$. Second, the structure parameter of FTIR suggests that the hydrogen enrichment parameter (average of 0.1 ) of Wolonghu coals is lower than that of Renlou coals (Table 3). Furthermore, the Wolonghu coals show a relatively low proportion of exinite compared with the Renlou and Taoyuan coal mines.

In summary, the heating rate affects pyrolysis. When the heating rate is high, the change of heat transfer rate from surface to interior of coal is inconsistent with that of heating rate. By contrast, the temperature gradient of each layer is relatively small, and the internal temperature is consistent. Therefore, the pyrolysis time of the inner layer only slightly differ. 


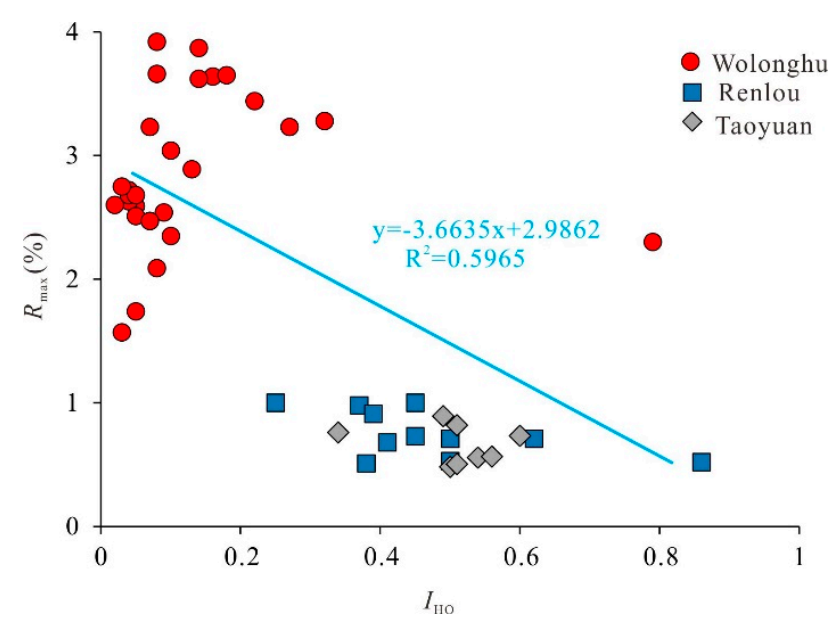

Figure 12. Correlation between $I_{H O}$ and $R_{\max }$ of selected coal samples in the Huaibei Coalfield.

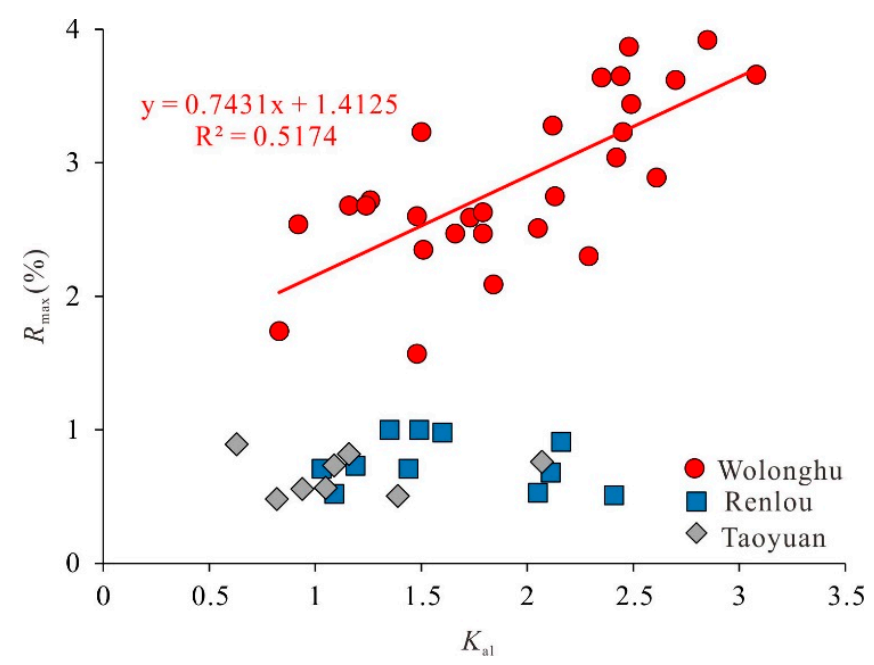

Figure 13. Correlation between $K_{a l}$ and $R_{\max }$ of selected coal samples in the Huaibei Coalfield.

\section{Conclusions}

The magma-altered coals in Wolonghu coal mine are mostly anthracite coals with maximum vitrinite reflectance of 1.6-3.9\% (average of 2.9\%). Differences in volatile matter content were observed between the magma-altered coals and unaffected coals from neighboring coal mines.

The maceral components of magma altered coals from Wolonghu coal mine are consisted of vitrinite group. The vitrinite content of unaffected coals from the Renlou and Taoyuan coal mines is higher than that of coals from the Wolonghu coal mine. In addition, the $R_{\max }$ shows no relationship with vitrinite, inertinite and exinite contents, the variations of which may be correlated with the corresponding depositional environments.

$\mathrm{H}$ element exhibits different intervals for the studied coal mines. The $\mathrm{H}$ element contents of coals from the Wolonghu, Renlou and Taoyuan coal mines are 1.9-3.5\% (average of $2.8 \%$ ), $4.2-4.8 \%$ (average of $5.1 \%$ ) and $4.8-6.0 \%$ (average of 5.5\%), respectively. The $\mathrm{H}$ content in unaffected coal is higher than that in magma-altered coal, and a phenomenon of "deficient in $\mathrm{H}$ element" is observed in the latter.

The parameter of aliphatic hydrocarbon structure revealed that the aliphatic chain of the coal samples from Wolonghu coal mine is shorter than that of samples from Renlou and Taoyuan coal mines.

At temperature of $0-450{ }^{\circ} \mathrm{C}$, the mass fraction of coal sample from Wolonghu coal mine is relatively stable at various heating rates. However, the mass fraction at $450-1000{ }^{\circ} \mathrm{C}$ changes greatly with different heating rates. 
Author Contributions: Writing—original draft, S.F.; Methodology, Q.W.; Writing—review \& editing, Q.W. and X.L. All authors have read and agreed to the published version of the manuscript.

Funding: This research was financially supported by National Natural Science Foundation of China (No. U1810201), the National Science and Technology Major Project of China (No. 2016ZX05007003), the Natural Science Foundation of Office of Education of Anhui Province (No. KJ2020A0732), Dual-ability teaching team project of Suzhou University (No. 2020XJSN06), demonstration teaching organization of Anhui Education Department (No. 416), and the start-up fund for doctoral research of Suzhou University (No. 2019jb20).

Institutional Review Board Statement: Not applicable.

Informed Consent Statement: Not applicable.

Data Availability Statement: Not applicable.

Conflicts of Interest: The authors declare no conflict of interest.

\section{References}

1. Jiang, M.M.; Liu, G.J.; Wu, B.; Zheng, L.G. Geochemistry of rare earth elements in coal from magmatic intrusion area from Wolonghu coal mine. J. Univ. Sci. Technol. China 2012, 42, 10-16.

2. Dai, S.F.; Ward, C.R.; Graham, I.T.; French, D.; Hower, J.C.; Zhao, L.; Wang, X.B. Altered volcanic ashes in coal and coal-bearing sequences: A review of their nature and significance. Earth Sci. Rev. 2017, 175, 44-74. [CrossRef]

3. Golab, A.N.; Hutton, A.C.; French, D. Petrography, carbonate mineralogy and geochemistry of thermally altered coal in Permian coal measures, Hunter Valley, Australia. Int. J. Coal Geol. 2007, 70, 150-165. [CrossRef]

4. An, Y.F.; Liu, L.L.; Wang, M.N.; Zheng, S.; Guo, Y.J.; Zhang, S.; Lai, C.K. Source and Enrichment of Toxic Element in coal seams around mafic intrusions: Constraints from Pyrites in the Yuandian coal mine in Anhui, eastern China. Minerals 2018, 8, 164. [CrossRef]

5. Huang, H.; Han, B.W.; Chen, S.D. Characteristics of REES in coals from the igneous intrusion area of the Zhuji Coal mine, Anhui. Bull. Miner. Petrol. Geochem. 2014, 33, 493-499.

6. Feng, S.B.; Yu, L.; Che, Q.S.; Liu, M.Q. Transition metal element geochemical characteristic at Wolonghu coal mine of Anhui province. Coal Geol. China 2015, 27, 8-10.

7. Kuboušková, S.; Krmíček, L.; Coufalík, P.; Pokorný, R. Petrological and geochemical characteristics of Palaeogene of low-rank coal on the Faroe islands: Restricted effects of alteration by basaltic lava flow. Int. J. Coal Geol. 2016, 165, 157-172. [CrossRef]

8. Wang, X.B.; Jiang, Y.F.; Zhou, G.Q.; Wang, P.P.; Wang, R.X.; Zhao, L. Behavior of minerals and trace elements during natural coking: A case study of an intruded bituminous coal in the shuoli mine, Anhui Province, China. Energy Fuels 2015, 29, 4013-4100. [CrossRef]

9. Wang, L.; Tang, D.Z.; Xu, H.; Li, S.; Pang, J.D.; Yao, C.H.; Li, J.J.; Yu, T.X. Magmatism effect on different transformation characteristics of coal reservoirs physical properties in Xishan Coalfield. J. China Coal Soc. 2015, 40, 1900-1910.

10. Mastalerz, M.; Drobniak, A.; Schimmelmann, A. Changes in optical properties, chemistry, and micropore and mesopore characteristics of bituminous coal at the contact with dikes in the Illinois basin. Int. J. Coal Geol. 2009, 77, 310-319. [CrossRef]

11. Chen, J.; Liu, G.J.; Li, H.; Wu, B. Mineralogical and geochemical responses of coal to igneous intrusion in the Pansan Coal mine of the Huainan coalfield, Anhui, China. Int. J. Coal Geol. 2014, 124, 11-35. [CrossRef]

12. Rahman, M.W.; Rimmer, S.M. Effects of rapid thermal alteration on coal: Geochemical and petrographic signatures in the Springfield (NO.5) coal, illinois Basin. Int. J. Coal Geol. 2014, 131, 214-226. [CrossRef]

13. Presswood, S.M.; Rimmer, S.M.; Anderson, K.B.; Filiberto, J. Geochemical and petrographic alteration of rapidly heated coals from the herrin (No.6) coal seam, Illinois basin. Int. J. Coal Geol. 2016, 165, 243-256. [CrossRef]

14. Ding, D.D.; Liu, G.J.; Fu, B.; Yuan, Z.J.; Chen, B.Y. Influence of magmatic intrusions on organic nitrogen in coal: A case study from the Zhuji mine, the Huainan coalfield, China. Fuel 2018, 219, 88-93. [CrossRef]

15. Shi, Q.L.; Qin, B.T.; Liang, H.J.; Gao, Y.; Bao, Q. Effects of igneous intrusions on the structure and spontaneous combustion propensity of coal: A case study of bituminous coal in daxing mine, China. Fuel 2018, 216, 181-189. [CrossRef]

16. An, Y.F.; Chen, Y.X.; Zhang, S.; Li, X.Y.; Lai, C.K. New discovery of post-magmatic pyrite in natural coke at Yangliu coal mine, Northern China. Acta Geol. Sin. 2018, 92, 2436-2437.

17. Zhao, L.; Ward, C.R.; French, D.; Graham, I.T. Major and Trace Element Geochemistry of Coals and Intra-Seam Claystones from the Songzao Coalfield, SW China. Minerals 2015, 5, 870-893. [CrossRef]

18. Wang, L.; Chen, Y.P.; Nie, Z.; Wang, H.F.; Yang, Y.; Liu, J. Effect of an extremely thick igneous rock on gas occurrence and outburst disasters in a coal seam. J. China Univ. Min. Technol. 2011, 40, 29-35.

19. Cheng, L.B.; Wang, L.; Cheng, Y.P.; Jin, K.; Zhao, W. Gas desorption index of drill cuttings affected by magmatic sills for predicting outbursts in coal seams. Arab. J. Geosci. 2016, 61, 1-15. [CrossRef]

20. An, Y.F.; Wang, M.N.; Liu, L.L.; Li, Y.F.; Cheng, J.; Liu, L. Microfabrics response of coal to magma among coal seam VIII in Yuandian Mine of Huaibei City, China. J. Coal Sci. Eng. 2017, 42, 2976-2980. 
21. Misz, M.; Fabiańska, M.J.; Ćmiel, S.R. Organic components in thermally altered coal waste: Preliminary petrographic and geochemical investigations. Int. J. Coal Geol. 2007, 71, 405-424. [CrossRef]

22. Wang, F.; Cheng, Y.P.; Jiang, J.; Wang, Y.L.; Shao, Z.J. Study on magma intrusion affected to coal properties of Daxing Mine. Coal Sci. Technol. 2015, 43, 61-65.

23. Jiang, J.Y.; Chen, Y.P.; Wang, H.F.; Zhou, H.X.; Jin, K. Effect of igneous intrusion on adsorption characteristics of coal to gas. J. Min. Saf. Eng. 2012, 29, 118-123.

24. Huang, X.Y.; Zheng, L.G.; Zhang, Q.W.; Hao, C.; Hao, C.; Yan, X.X.; Han, Y.Y. Distribution and models of occurrence of mercury in coal seams altered by magmatic hydrothermal from Wolonghu coal mine. Geol. J. China Univ. 2015, 21, $280-287$.

25. Ou, J.P.; Zheng, L.G.; Wei, X.P.; Liu, S.K.; Liu, L.Y.; Liu, M.; Huang, X.Y. Occurrence of antimony in magmatic intrusive coal seam A case study from the Wonglonghu coal mine, Huaibei coalfield, China. Coal Geol. Explor. 2019, 47, $63-68$.

26. Jiang, J.Y.; Cheng, Y.P.; Wang, L.; Li, W.; Wang, L. Petrographic and geochemical effects of sill intrusions on coal and their implications for gas outbursts in the Wolonghu Mine, Huaibei Coalfield, China. Int. J. Coal Geol. 2011, 88, 55-66. [CrossRef]

27. Sun, Q.L.; Li, W.; Li, B.Q. Pyrolysis of shenmu coal macerals and kinetics analysis. J. Chem. Ind. Eng. 2002, 53, $1122-1127$.

28. Sarana, S.; Kar, R. Effect of igneous intrusive on coal microconstituents: Study from an Indian Gondwana coalfield. Int. J. Coal Geol. 2011, 85, 161-167. [CrossRef]

29. Rimmer, S.M.; Yoksoulian, L.E.; Hower, J.C. Anatomy of an intruded coal, I: Effect of contact metamorphism on whole-coal geochemistry, Springfield (No. 5) (Pennsylvanian) coal, Illinois Basin. Int. J. Coal Geol. 2009, 79, 74-82. [CrossRef]

30. Yang, S.F.; Feng, S.B. Pyrolysis Characteristics of Different Maceral of Coal in Renlou Coal Mine of Huaibei Coalfield. J. Xichang Univ. 2019, 33, 39-42.

31. Li, F.; Zhang, Y.F.; Xie, K.C. Effect of the mineral matter on the pyrolysis reaction of Coal Macerals. J. Fuel Chem. Technol. 1992, 20, 301-306.

32. Ibarra, J.; Moliner, R.A.; Bonet, A.J. FT-IR investigation on char formation during the early stages of coal pyrolysis. Fuel 1994, 73, 918-924. [CrossRef]

33. Sun, X.G.; Chen, J.P.; Hao, D.H. Micro-FTIR spectroscopy of macerals in coals from the Tarim basin. Acta Sci. Nat. Univ. Pek. 2001, 37, 832-838.

34. Kus, J. Impact of underground coal fire on coal petrographic properties of high volatile bituminous coals: A case study from coal fire zone No.3.2 in the Wuda Coalfield, Inner Mongolia Autonomous Region, North China. Int. J. Coal Geol. 2017, 171, 185-211. [CrossRef]

35. Stach, P.; Natkaniec-Nowak, L.; Wagner, M.; Dumańska-Słowik, M.; Mroczkowska-Szerszén, M.; Wesełucha-Birczyńska, A.; Drzewicz, P.; George, C.; Garcia, E. A Study on the Formation Environment of the La Cumbre Amber Deposit, from Santiago Province, the Northwestern Part of the Dominican Republic. Minerals 2020, 10, 736. [CrossRef]

36. Li, M.; Lyu, S.; Jiao, X.W. Experimental study on influence of included minerals on the char combustion characteristics. Coal Conver. 2009, 32, 34-36.

37. Wu, F.X. The influence of mineral on the coal reactivity. Coal Geol. China 1993, 5, 49-52.

38. Zhao, H.Y.; Li, Y.H.; Song, Q.; Lyu, J.X.; Shu, Y.F.; Wang, Z.M.; Yan, J.; Zeng, M.; Shu, X.Q. Effect of additive ironore on pyrolysis characteristics of a low rank coal from Hami. J. Fuel Chem. Technol. 2016, 44, 155-161.

39. Zhao, Y.H.; Lin, J.Y.; Chang, L.P. The effect of mineral matter on the $\mathrm{NH}_{3}$ formation during Coal Pyrolysis and gasification. Environ. Chem. 2004, 23, 26-30. 